\title{
Economics as a Humanitarian Science
}

\author{
"Economic Rhetoric" of McCloskey as a Case Study*
}

\author{
Andrey Orekhov \\ Department of Social Philosophy \\ Peoples' Friendship University of Russia \\ Moscow, Russia \\ orekhovandrey@yandex.ru
}

\author{
Fakhraddin Akhmedov \\ Department of Finance and Credit \\ Peoples' Friendship University of Russia \\ Moscow, Russia \\ akhmedov@mx.rudn.ru
}

\begin{abstract}
This article is devoted to the understanding of an economic science known as "humanity". In an economic science, a problem of economic interpretation is rather significant: it investigates the importance of economic concepts and statements. The American economist D. McCloskey has criticized the modern economic science from positions of economic rhetoric. The economic rhetoric of $\mathrm{D}$. McCloskey criticizes economy for neglect objectivity principles, an inattention to the text that has "implicit" and "personal" character of economic theories and hypotheses and considers economic science as a special case of literary criticism. In practice, this criticism repeats already known conclusions of $M$. Veber, M. Polani, P. Feyerabend and other known methodologists and only contains ascertaining of the fact that the economy also is "humanity".
\end{abstract}

Keywords-economics; communication; text; rhetoric; humanitarian science; McCloskey

\section{INTRODUCTION}

Social sciences and the humanities study the same object - the person and a society, but under a different point of view: social sciences are more interested in a society, but humanitarian studies are more interested in the individual.

Let us make definition that is more exact:

Social sciences - they are the sciences studying a society, whose main signs are:

- Orientation to construction of social knowledge on model of natural sciences - mathematicians, physicists, biology; or, speaking differently, "imitation" natural sciences in methodology and theory;

- Accent on studying of social interaction and social communications, - in a counterbalance to personal, individual, especial characteristics of the individuals entering these interactions and communications; social sciences investigate first of all a society, and then individuals, this society's components;

*This paper was financially supported by the Ministry of Education and Science of the Russian Federation on the program to improve the competitiveness of Peoples' Friendship University of Russia (RUDN

University) among the world's leading research and education centers in the 2016-2020
- An emphasis on studying of objective characteristics of social interaction, - thus the subjective component of these interactions is rather minimized.

One of the main differences of social sciences from the humanities consists in orientation of social sciences to natural-science model of designing of scientific knowledge:

Social sciences are obliged by considerable the number of characteristics and the difficulties to that fact that they also have begun the way much after other sciences. For example, they can consciously or unconsciously use models of more advanced sciences to simulate the scientific character [1].

The humanities are the sciences which overall objective is studying of the person against a society and working out specific methodology, - distinct from methodology of natural sciences.

Particularly it is expressed in following characteristics:

- The humanities adhere own, humanitarian, methodology of construction of knowledge of a society, - "without imitating" natural sciences and without being guided by their methodology;

- In social interaction of individuals, the emphasis is placed on studying of their personal, especially, individual characteristics, - even to the detriment of the analysis of the interaction;

- The basic object of research in the humanities is the text, and the primary goal - interpretation of this text for the purpose of achievement of its full understanding;

- The humanities are dialogic: they are interested in individuals who say something, and those individuals that enter dialogue with each other speaking something to each other on purpose to understand the sense of the said; in this aspect, the humanities are in a greater degree communicative, than social sciences.

What sciences can be considered "social" and what as "humanitarian"?

As we marked already in the paragraph beginning, division of sciences on "social" and "humanitarian" is rather 
conditional. Any social science to some extent is humanitarian, and any humanity to some extent is social. Nevertheless, there are sciences more "social" than "humanitarian" and vice versa.

"Social sciences" concern more economics, political science, jurisprudence, sociology, and social ecology. "Humanitarian" focuses more on cultural science, and philology. The disciplines in which it is equally presented both "humanitarian" and "the social" sings are philosophy, history, anthropology, pedagogics, psychology, and gender researches.

The given classification can also be presented as following in the "Table I":

TABLE I. ClasSIFICATION OF SCIENCES

\begin{tabular}{|c|l|}
\hline Social sciences & $\begin{array}{l}\text { Economy, political science, } \\
\text { sociology, jurisprudence, social } \\
\text { ecology }\end{array}$ \\
\hline The humanities & Philology, cultural science \\
\hline Socially-humanity & $\begin{array}{l}\text { Philosophy, history, anthropology, } \\
\text { pedagogics, psychology, gender } \\
\text { researches }\end{array}$ \\
\hline
\end{tabular}

As a result, it is possible to make the approximate list of the basic social sciences: 1) Philosophy (social philosophy, ethics, social epistemology); 2) History; 3) Anthropology (social anthropology); 4) Pedagogics; 5) Psychology (social psychology); 6) Cultural science (social cultural science); 7) Economy; 8) Political science; 9) Sociology; 10) Jurisprudence; 11) Gender researches; 12) Social ecology.

In our opinion, the basic humanitarian disciplines concern: philology; cultural science (in the most part); psychology of the person; coniology; anthropology (in the most part, cultural anthropology); philosophy (philosophical anthropology); and in some part - history; pedagogics; gender researches» [2].

\section{COMMUNICATION AND TEXT: UNIVERSAL IDEA}

How do we define the importance of communications in a modern society? To answer this uneasy question, we will try to start from I. M. Saveleva's and A. V. Poletaev's statement, asserting that communications operate, if subjective senses of actions get character intersubjective values, common for all co-operating subjects [3]. Hence, communications are extremely important for a modern society for it conducts to an establishment of dialogue, the consent and justice.

But how to define communications? Here it is possible to refer to I. P. Yakovlev's definition:

Communications - are a process in which the communicant sends (initiate) messages, using conditional symbols, nonverbal signs and keys to a context, expressing values and transferred in such a manner that the addressee, to whom they are directed, creates similar or parallel understanding [4].

In an initial approach, communications can be defined as the exchange of messages allowing subjects, entering communications, to have similar interpretations of sent messages. Naturally, there is always a danger of a distortion of the meaning of these messages:

The sense for the recipient can be close to sent value or to differ from it depending on the subjective relation of the addressee. Here there is an infringement and discrepancy of perception of the information or its revaluation [5].

As to inter subjectivity - it is possibility of coincidence of subjective senses of two or more co-operating subjects in which a result of subjective senses can find objective value for the given subjects.

The basic for coincidence of such senses is created by dialogue.

Dialogue is the interaction between two or more subjects for the purpose of condition achievement inter subjectivity.

The text has a great importance for such dialogue and for process of understanding of another.

The text is certain sign complex, capable to create new senses.

\section{G. Gadamer confirmed concerning the text:}

The [texts] should be interpreted and understood not only what they say, but also what in them and through them testifies to itself ...

It is necessary to interpret there where the meaning of the text cannot be understood directly [5].

More important are the concepts of "interpretation" (logical interpretation) as a way of perusal of "text": interpretation - as research of value of concepts and statements in the text.

For example, in an economic science, there is the economic interpretation:

Economic interpretation (interpretation of economic concepts) - is the major component of the economic analysis which can be treated as a special method of an economic science. The purpose of economic interpretation is research of major importance (semantic values) those or other economic concepts or statements. From what economic value will be attributed to this or that concept or the statement, the understanding of all subsequent economic conclusions our opponents will depend or is simple interlocutors or readers [6].

\section{III. "HUMANITARIAN" CRITICISM OF ECONOMICS BY MCCLOSKEY}

Donald McCloskey - an American economist is the critic of a modern economic science from positions of so-called economic rhetoric. The basis for such criticism became aggressive (even "extreme") positivism and naturalism of modern D. McCloskey economy, traditionally designated by the term economics. Rigid formalization, mathematized, propensity simultaneously both to naked empiricism, and to superficial mathematical theorization have caused D. McCloskey's (and not only of him, naturally) extreme 
aversion. This aversion has forced D. McCloskey to begin criticism of such positivism with positions of so-called economic rhetoric, by which D. McCloskey meant, as a whole, the philological analysis of texts and language modern to it of the economic literature for the purpose of revealing in it of various omissions and the errors conducting to decrease of level of scientism in economics, to easing system of its proofs and qualities of the argument.

\section{As D. McCloskey declares:}

Our problem is to dethrone the exclusive power of the Science in economy, having called into question necessity of differentiation of a science from art. To show that the economy is similar to literary criticism and philology, and the social theory can excite economists guesses or force to shudder from violence over the nature in the same way as it does the physicist of elementary particles and building of dams [7].

Between economy and rhetoric, it is possible to spend the following analogy:

The rhetoric is an economy's language, a science how to redistribute poor means for satisfaction of tireless desire of people to be heard [7].

Economists, according to D. McCloskey, strongly underestimate a role of various rhetorical receptions in their own scientific economic language, and it is their obvious omission.

The serious argument will involve in a science both metaphors, and stories - and not only ornaments or lectures, but also for the sake of the science ... If we as readers of the scientific literature are going to go further a kindergarten, it is necessary for us to extend such rhetoric to an economic science [7].

These economists as do not know that, being engaged in research in the field of economy, they simultaneously are engaged also in literary criticism, - with use of the same receptions that is, for example and in literary criticism: metaphors, allegories, etc.: The economic theory can be considered as a special case of literary criticism [7].

\section{Is D. MCCLOSKEY RIGHT IN HIS CRITICS OF ECONOMICS?}

Here a natural question arises: how much is D. McCloskey right in his criticism of economics? How much of his criticism is reasonable, fair and proved? Whether it is possible, for example, after acceptance of arguments of the American economist to declare that the economy became not only "social", but also "a humanitarian" science, like philology, cultural science, or literary criticism?

Authors of the article have a basis to assert that all arguments of D. McCloskey in advantage of economic rhetoric represents a certain syncretic vinaigrette, i.e. in it there are mixed arguments of various levels, it is necessary to recognize some of them weighty and proved, but others weak and unsubstantiated. To understand this "vinaigrette" is a difficult problem, though feasible; we will try to make it below.

We will begin with the main argument of D. McCloskey, - he asserts that the economy - is the humanity.

But after all anybody never also did not confirm the opposite! Here, in this point, a critic D. McCloskey beats to tell without exaggeration in "milk". In the first section of this article, we proved. It's not only our argument but an argument of all philosophers of science that any social science is to some extent humanity, and any humanity is to some extent social. There are no strictly "humanitarian" sciences nor strictly "social" sciences, and the same concerns an economic science. Yes, it is more social, but also somewhat humane and when D. McCloskey declares that we assert that all sciences are humanity (and never in a pure kind), after all everything in it [economy] is intended for the person [7], he declares an obvious and banal thing for the majority of philosophers of a science, - both "western" and others.

Yes, it is quite possible to consider economy as "humanity". There is also a text, both concepts, and hermeneutic interpretation of concepts and the economic anthropology with economic concepts as the two most important parts of the philosophy of economics, both attempt to adjust dialogue and communications between various subjects creating economic knowledge. However, to designate an economic science as "humanitarian" should be with reservations and reasonable care. An incorrect statement of a question can destroy existing communication between "social" and "humanitarian". Accents in the given science are built nevertheless in advantage of social but completely not humanitarian knowledge.

The second problem, with all clearness and completeness designated by D. McCloskey is a problem of "values" in economic thinking, a problem of a parity subjective, personal and objective, real in economic knowledge. It is necessary to recognize that this problem is one of the most discussed in economic methodology of the second half of the 20th century to the beginning of the $21 \mathrm{st}$ century. Conclusions to which the majority of researchers on this problem come is -any economic knowledge includes not only real judgement, but also valuable interpretation of this judgement. Such interpretations can be seen in an overwhelming majority of economic theories and hypotheses, including formalized, mathematical character. Mathematics here is only panacea for decision of question, but this problem is so obvious and so repeated that it was reproduced on pages of economic magazines and monographies that it is unclear how D. McCloskey does not notice this problem and ignores all statements of authorities in this area (J. Shumpeter, M. Freedman, F. Mahlup, D. Hausman, etc.). Reading classics would not bring the American economist to such radical negation to an economic science.

The third problem, which is a doubtless element of critics of D. McCloskey, is a problem of so-called personal knowledge for the first time put by the American scientist Michael Polani in his work "Personal Knowledge" [8]. M. 
Polani underlined that any scientific knowledge (including economic) comprises a considerable "implicit", "inexpressible" element; such knowledge substantially is personal knowledge, and to attempt transfer it to another can be connected with great difficulties.

In consequence to a silent character of our knowledge, we never can state everything that we know, in the same way, as because of a silent character of knowledge we can never know all that implicated in our statements [8].

However, it is necessary to underline that personal character of knowledge basically is the characteristic that is not scientific but ordinary economic knowledge [6], and D. McCloskey attributes to its a priori modern economic science. One of the purposes of scientific knowledge also consists in minimizing a level of "personal" and "ordinary" in scientific knowledge and methodology to make the last as much as possible accessible to any scientist wishing to apply to them. It is strange that D. McCloskey does not notice this fact.

The fourth problem regarding the economic rhetoric of $\mathrm{D}$. McCloskey is directly connected with the general aspects of the science critics, following well-known methodological anarchism of P. Feyerabend. Like D. McCloskey, Feyerabend asserted (and long before the occurrence of work from D. McCloskey) that science as the social institute represents the anarchist enterprise.

Science represents, as a matter of fact, the anarchist enterprise: the theoretical anarchism is more humane and progressive, than its alternatives leaning on the law and an order [9].

The principle of equality of all kinds of knowledge conducts ascertaining a key idea of "methodological anarchism: Anything goes! - All will descend! The unique principle, which is not interfering progress, is: "all is admissible" (anything goes) [9].

What principal cause on which the scientific knowledge is not capable to rise above other kinds of knowledge?

It, according to P. Feyerabend, roots in science. All attempts to co-ordinate empirics and the theory are unpromising, - it is necessary to trust neither the first nor the second. Empirics - supervision and experiment, in general, is something like the "trojan horse" in science, - attempt to drag it in to pure theory, each time turns around that from a horse jump out enemies and destroy the theory.

As a whole, a science with its "objectivity" is one of mythology variants.

Thus, science is much closer to a myth than scientific philosophy is ready to suppose. It is one of many forms of thinking developed by people, and it may not be the best. It blinds only those who have already made the decision in favor of certain ideology or does not reflect at all on advantages and science restrictions [9].

It is impossible to tell that $\mathrm{D}$. McCloskey directly agrees with Feyerabend in this point, but his desire "to dethrone the exclusive power of the Science in economy" very strongly means "methodological anarchism". Authors of this article pay a tribute to ideas of Feyerabend and recognize their importance for understanding development of a science. Nevertheless, in the main point with him, the authors categorically do not agree: a science is not anarchist, but quite regular, rationally well-founded and experimentally proved "enterprise". Science and mythology have directly opposed each other. Complexity of interaction of the theory and empirics is obviously exaggerated by Feyerabend, no "self-abasement" and theory "self-destruction" in a science is present; it remains the main form of existence of scientific knowledge in a science. Therefore, the attempt of $D$. McCloskey to obviously or implicitly borrow ideas from Feyerabend to us is not represented as serious and proved.

The fifth problem discussed by D. McCloskey, is a problem connected with manipulation economic knowledge. Also, it is necessary to recognize this fact as doubtless: economists are the specific social group, as a big part of intellectuals, that are capable imposing other social groups specific visions of social processes. In this point, D. McCloskey reminds us that deconstruction is one of the basic methods of postmodernist philosophy, and, in this case, he is right from all points of view.

Among the merits, fairly made deconstructivists, we will note the concept of hierarchical verbal signs. Its essence is simple and is reduced to that words bear in themselves concerning the antonyms. Therefore, the word faithless causes a word Moslem in memory, and black forces to recollect an adjective white... Hierarchical distribution in the text parades political intention [7].

One of authors of this article has put this problem but in wider aspect (as a problem of manipulation of intellectual property) and marked concerning the possibilities, existing "economists'" specific parts of intellectual proprietors:

Economists - one more group inclined to active use of manipulative of intellectual property, though it is less possible than two others (lawyers and journalists). But the unflattering epithet most of all approaches to this group of intellectual service staff of business used by us in the previous paragraph. It is possible to find out the original paradox of existence of this group: on the one hand, owing to high level of rationality and efficiency of economic knowledge (and possibility of its verification), it aspires to deliver on the market as much as possible trustworthy information and to avoid any manipulations with it, but on the other hand, and owing to the social order of managers material proprietors of the capital. They are compelled to go often on distortion of this information, representing it in favor of the customer and using it as means of pressure and manipulation for social groups and layers to which this information is inaccessible initially. Distortion of tax declarations, the financial reporting, macroeconomic or microeconomic indicators, obviously manipulative activity in sphere of public relation. For the purpose of rendering of pressure or reception of any benefits, it is only few possible ways on which moves manipulative consciousness of economists. But the same result has manipulative activity of lawyers and journalists [10]. 
As a whole, manipulation can be defined as a way of influence of the person (a society, social group) on the person (a society, social group) at which transfer of the necessary information from the subject of manipulation to object of manipulation is carried out in the latent, disguised way. Therefore, the object of manipulation is compelled to recognize handed over to him the subject of manipulation the information proceeding as though from himself and from the person without finding out the influence of the subject of manipulation.

However, it is necessary to notice that manipulation is only one way of influence on the person, social group or society which main sign is disguised. By that, manipulation cardinally differs from other well-known ways of influence on the person - "propagation" when the information is transferred in the open way and the object of such influence can easily specify its subject (political party, the state, etc.).

At last, the sixth point concerning critics of $D$. McCloskey of an economic science. That D. McCloskey designates as the economic rhetoric actually is the beautiful metaphor, which is not related to real rhetoric as to a science about eloquence. The rhetoric as an art and a science about eloquence in practice differs from those problems, which are discussed by D. McCloskey as to the lawyer representing on court any party; it is deeply indifferent if the party protected by him is right or not. Criticizing manipulation by economists are true. D. McCloskey does not notice that he manipulates the term "rhetoric" and the term in his lips gets manipulative character. Yes, he wishes to prove that it is right, and, is valid in many respects, but from the point of scientific ethics, it is a manipulation towards both the colleagues-economists and the people ignorant of economy. Possibly, deeper and funded analysis by the American economist would shift its criticism not to the superficial term of "rhetoric" but to much more essential and significant interpretation of economy as humanity. Here again is designated a border which could not pass by D. McCloskey: humanitarian, valuable, personal, and manipulative character of modern economic knowledge, namely this problem also requires the further research, - both economists-methodologists, and philosophers of a science.

\section{CONCLUSION}

So, it is possible to draw following conclusions from our article.

- The humanities - is the science, the overall objective of which is to study a person against a society and to work out one's own, specific methodology, - distinct from methodology of natural sciences. The economy also can be considered to a certain extent as humanity.

- Communications - this is a process in which a communicant sends (initiate) messages, using conditional symbols, nonverbal signs and keys to a context, expressing senses and transferring in such a manner that the addressee to whom they are directed, creates similar or parallel understanding. The text is a certain sign complex, capable to create new senses. The purpose of economic interpretation is a research of major importance (semantic values) those or other economic concepts or statements.

- The economic rhetoric' of D. McCloskey criticizes economy for neglect objectivity principles, an inattention to the text, 'implicit', 'personal' character of economic theories and hypotheses, and considers an economic science as «a special case of literary criticism».

- The Economic knowledge has humanitarian, valuable, personal, changeable character, and such interpretation demands more profound and funded researches concerning the nature of this knowledge.

\section{REFERENCES}

[1] P. Bourdieu, Beginnings, Moscow: Praxis, 1994, p. 63.

[2] A. M. Orekhov, Social sciences as subject of philosophical and sociological discourse. Moscow: INFRA-M, 2014, pp.13-14.

[3] A .M. Savelyeva, A. V. Poletaev, Sociology of knowledge in the past. Moscow: Roza Vetrov Publishing, 2005, p. 45.

[4] I. P. Yakovlev, Basis of communication theory: Saint Petersburg: VSE, 2001, pp. 21-22.

[5] H-G. Gadamer, Truth and method: Moscow: Progress, 1988, p. 397

[6] A. M. Orekhov, Methods of economic researches: Moscow: INFRAM, 2013, p. 133, pp. 124-125.

[7] D. McCloskey, Rhetoric of economics, Moscow-Saint Petersburg: Gaydar Institute, 2015, pp. 31, 3, 26-27, 48, 32, 23.

[8] M. Polanyi, Personal knowledge. Moscow: Progress, 1985, p, 140.

[9] P. Feyerabend, Selected works on methodology of science. Moscow: Progress, 1986, pp. 147, 153, 450.

[10] A. M. Orekhov, Intellectual Property as the Object of SocialPhilosophical and Social-Theoretical Research: Moscow: URSS, 2009. pp. $149-150$ 